\title{
ESPARTACO Y LA LUCHA DE CLASES EN EL HOLLYWOOD DE McCARTHY
}

\author{
Carolina FRÍAS CASTILLEJO \\ Universidad de Alicante
}

Y en tanto que el hombre trabaje y otros hombres tomen y usen el fruto de los que trabajan, el nombre de Espartaco será recordado.

Howard Fast, Espartaco.

\begin{abstract}
¡Atención comunistas, espías, traidores y agentes extranjeros! ¡El Capitán América, con todos los leales hombres libres detrás, os vigila! Jack Kirby y Joe Simon, Capitán América.
\end{abstract}

La película Espartaco, dirigida por Stanley Kubrick, está basada en la novela homónima publicada en 1951, un año después de que su autor, Howard Fast, cumpliera una condena de tres meses de cárcel por no delatar a otros miembros del Partido Comunista de Estados Unidos. Este dato es clave para entender la novela y su adaptación cinematográfica, ya que ambas obras son un alegato, una defensa de unas ideas políticas prohibidas y perseguidas en la América de los años 50 y 60 del siglo XX.

En muchos casos el cine es empleado por el poder para expresar y comunicar su ideología de forma más o menos evidente, convirtiéndose en ocasiones la película en un panfleto político donde se difunden las bases ideológicas de la clase gobernante. Sirva como ejemplo la obra de Sergei Einsestein, Acorazado Potemkin (1925) donde se hace una relectura de la revolución rusa de 1905, o Raza (1941), una de las mejores muestras de propaganda franquista en el cine español. El caso de Espartaco es atípico en este sentido, ya que, empleando los mismos recursos que la propaganda gubernamental, se hace en la película una crítica a la situación política del momento y una reafirmación de las ideas prohibidas en un período en que el mundo del cine y de la literatura estaban sometidos a una fuerte censura.

Esta película y la reflexión que realizamos a continuación forma parte de los contenidos de las asignaturas de Historia Antigua Universal II de la Licenciatura en Historia de la Universidad de Alicante, impartida por el profesor Jaime Molina Vidal y La Historia de Roma en el séptimo arte: los encantos de Cleopatra y el enfrentamiento 
entre Octavio y Marco Antonio, impartida también por el profesor Molina junto con la autora en la Universidad Permanente de Alicante. Los objetivos que se han planteado desde una perspectiva didáctica son los siguientes:

- Valorar el cine como herramienta para la didáctica de la historia.

- Determinar de qué manera influye el lenguaje cinematográfico en nuestra visión de la historia.

- Establecer en qué medida el peplum es válido en la enseñanza de la Historia Antigua.

- Mostrar la imagen de Espartaco como héroe revolucionario en época contemporánea.

- Expresar la existencia de un doble lenguaje en las obras de arte en general y, en particular, en el cine y la literatura.

\section{La caza de brujas}

Las relaciones internacionales estadounidenses desde el fin de la Segunda Guerra Mundial están basadas en el enfrentamiento con el bloque comunista y, en este contexto, el apoyo soviético a los movimientos de liberación colonial y a las alianzas creadas con los países de Europa del Este se veía como una peligrosa expansión del comunismo que era necesario detener. El bloqueo soviético de Berlín, el triunfo del comunismo en China, la guerra de Corea..., todos estos conflictos ayudaron a crear un clima de cierta histeria social y de xenofobia frente a todo lo que representaba el comunismo. El anticomunismo pasó a formar parte también de la política interna, poniendo freno a las reivindicaciones sindicales y al concienciamiento social producido en los años 30 en el marco del New Deal.

Los grupos sociales y económicos más conservadores empezaron a temer una rebelión de los elementos izquierdistas y, como respuesta a este clima de tensión, la sociedad estadounidense de los años 50 estará marcada por un fuerte conservadurismo, donde la creación intelectual se veía como algo sospechoso, por lo que la aparición de un personaje como McCarthy no resulta del todo extraña. Esta tendencia conservadora afecta no sólo a los republicanos, sino también a los demócratas, creándose un ambiente de patriotismo con la sensación de que los modos de vida tradicionales estaban en 
peligro. Todo ello provocó el rechazo a cualquier elemento izquierdista, visto como algo contrario a la esencia americana.

Es en este contexto histórico donde debemos encuadrar la creación del Comité de Actividades Antiamericanas en 1947, un comité del Senado desde el que se llevó a cabo la llamada caza de brujas. Ya en 1946 se elaboran unas listas en el Departamento de Estado donde se incluyen individuos potencialmente peligrosos para la sociedad americana: comunistas, por supuesto, pero también fascistas, homosexuales y alcohólicos. Los ámbitos donde actuaba el comité fueron todas aquellas organizaciones e instituciones sospechosas de albergar "comunistas": sindicatos, asociaciones de derechos civiles, universidades, etc. McCarthy llegó incluso a poner bajo sospecha al general Marshall, Secretario de Estado en 1947. Toda actividad intelectual resultaba sospechosa y más de 30.000 libros fueron retirados de las librerías acusados de albergar contenidos comunistas. Muchos cineastas y escritores tuvieron que emigrar de Estados Unidos, entre ellos Charles Chaplin, Orson Welles y Bertolt Brecht. La actuación del Comité en el cine, la televisión y la prensa pretendía obtener el control de unos medios de comunicación que se estaban convirtiendo en herramientas fundamentales de propaganda en la nueva sociedad de consumo surgida a partir de la Segunda Guerra Mundial.

El ambiente de crispación y miedo, ya fuera real o creado, en que vivía la clase política propició la formación de este comité, dirigido por el senador republicano por Wisconsin, Joseph R. McCarthy. El procedimiento de actuación eran las delaciones de los acusados, a quienes se prometía la exclusión de las black list, las listas negras donde se registraban a aquellos considerados culpables de alguna actuación antiamericana y, por tanto, ilegal. La mayoría de las acusaciones eran falsas y desproporcionadas, además de que no se contaban con pruebas reales de esas supuestas actividades ilegales. En octubre de 1947 tienen lugar las primeras imputaciones de personas de Hollywood, diez cineastas -the Ten of Hollywood- que fueron encarcelados un año, acusados de pertenecer al Partido Comunista. Uno de estos cineastas fue Dalton Trumbo, autor del guión de la película Espartaco, quien entró en la lista acusado por un compañero del Partido Comunista. Como consecuencia de haber estado en las listas de McCarthy, Trumbo tuvo que trabajar con seudónimo hasta el estreno de Espartaco en 1960, cuando por primera vez un miembro de la lista emplea su nombre para firmar un trabajo.

El fin del macartismo se produce en 1954, en el momento en que el senador comienza a investigar posibles actividades comunistas en el ejército. Es precisamente 
con un presidente republicano, Eisenhower, cuando se produce el cese de McCarthy en medio de una campaña de descrédito, muriendo tres años después a causa de una cirrosis.

\section{El mito de Espartaco}

En el cine americano de los años 50 y 60 se pone de moda el peplum, un género de grandes superproducciones con espectaculares escenarios que pretendía competir con la televisión. Quo Vadis (1951), Cleopatra y Ben-Hur (1963), La caída del Imperio Romano (1964), son películas ambientadas en la Antigüedad en las que se transmiten unos valores tradicionales, donde la virtud acaba imponiéndose al vicio, la lujuria o el ansia de poder. Pero, ¿y Espartaco?, ¿se puede incluir dentro del género del peplum? La película cuenta con todos los elementos propios de una aventura: el héroe -Espartaco-, la chica -Varinia-, el malo -Craso-, batallas, luchas de gladiadores, una historia de amor y un final trágico, pero esperanzador. Sin embargo, si hacemos una lectura más allá de estos elementos, si tenemos en cuenta el ambiente de fuerte censura y represión de toda idea liberal y de izquierdas de la época, si conocemos las circunstancias del guionista y del autor de la novela, podremos extraer un sinfín de claves que nos conducen a una lectura diferente de la película que hace que se distancie de las típicas películas de romanos. Su éxito -ganó 4 Óscars y es considerada actualmente un clásico- está en que la defensa de los postulados comunistas, la intencionalidad del autor, aparece enmascarada en una historia épica bien contada que en nada se asemeja a un panfleto político.

Antes de continuar analizando la figura de Espartaco, resumamos brevemente la película. Espartaco (Kirk Douglas) es un esclavo tracio que trabaja en las minas y que, siendo adulto, es vendido a la escuela de gladiadores de Léntulo Batiato (Peter Ustinov) en Campania. En la escuela conoce a la esclava britana Varinia (Jean Simmons) de la que se enamora. Una revuelta de los gladiadores iniciada por un hecho casual da lugar a una rebelión de los esclavos campanos que, poco a poco, se van adhiriendo a la causa ansiando la libertad proclamada por Espartaco. Tras vencer a los romanos y recorrer gran parte de Italia, los esclavos intentan huir por Brindisium (Brindisi) ayudados por los piratas cilicios quienes, en el último momento, los traicionan. Finalmente tiene lugar una batalla entre los romanos, liderados por Craso (Lawrence Olivier), y los esclavos 
que, como era previsible, pierden los hombres de Espartaco. Todos ellos vuelven a su condición de esclavos y, como castigo, muchos son crucificados en la vía Apia.

La elección del protagonista y de la historia es ya un indicador de la intencionalidad de Trumbo y Fast. Espartaco y su revuelta de esclavos representa, para la historiografía marxista, el paradigma de rebelión proletaria contra el capitalismo y se identifica como el desencadenante de la crisis de la agricultura itálica a finales de la República. Los esclavos, por tanto, son el proletariado de la Antigüedad con conciencia de clase oprimidos por los latifundistas romanos. La figura de Espartaco va más allá de interpretaciones académicas de la historia, especialmente en la URSS, pero también en otros países europeos, como la Alemania de entreguerras, donde los comunistas de Rosa Luxemburgo se autodenominaron espartaquistas ${ }^{1}$. El gladiador ha sido representado en gran cantidad de medios artísticos -ballets, piezas musicales, obras pictóricas, esculturas- e incluso da nombre a un evento deportivo soviético similar a las Olimpíadas y a dos equipos de fútbol -el Spartak de Moscú y el Spartak de Praga-.

Karl Marx define a Espartaco como el máximo exponente del proletariado antiguo, cuando los esclavos en la Antigüedad distaban mucho de tener conciencia de clase, ya que legalmente ni siquiera eran considerados personas, sino instrumentum vocale, es decir, meras herramientas parlantes. La revuelta no tuvo ninguna consecuencia real para el estado romano -Craso no obtuvo el triunfo por esta acción militar-y, si tuvo una duración mayor de la esperada y ganaron algunas batallas, fue porque Roma tenía en esos momentos otros frentes abiertos más importantes ${ }^{2}$. Su papel en la crisis de la agricultura también es mínimo, puesto que la rebelión fue un mero episodio que en nada contribuyó al declive del modo de producción esclavista imperante en la economía del sur de Italia durante los siglos II y I a.C.

Espartaco es presentado en el prólogo de la película como un esclavo de nacimiento que desde niño "soñó con la abolición de la esclavitud". Pero, ¿quién fue Espartaco? Las fuentes escritas ${ }^{3}$ nos indican que en realidad era un soldado tracio helenizado que formaba parte de las tropas auxiliares del ejército romano y que posteriormente fue vendido como esclavo para ser gladiador. Howard Fast conocía las

\footnotetext{
${ }^{1}$ Para tener una visón más amplia del papel de Espartaco como símbolo resulta interesante el artículo de J.M. Blázquez y J. Cabrero publicado en 2004 "Un mito universal. Espartaco", La Aventura de la Historia, 63, pp. 84-89.

${ }^{2}$ Un análisis del desarrollo histórico en que está basado la película se puede encontrar en FATÁS, G., 1999: "Espartaco, de S. Kubrik", UROZ, J. (ed.), Historia y cine, Alicante, pp. 63-78.

${ }^{3}$ cfr. FATÁS, G., 1999: "Espartaco...", pp. 72-75.
} 
fuentes clásicas, pero prefirió dotar de un pasado más trágico al personaje con el fin de aumentar las connotaciones épicas de su hazaña.

\section{El análisis de la película}

La película transmite una serie de principios ideológicos estrechamente vinculados con la filosofía marxista: la lucha de clases, la conciencia de clase, la igualdad entre los proletarios, la corrupción del sistema capitalista y la internacionalidad de la revolución socialista. También se proponen situaciones asimilables con el ambiente anticomunista existente en la época y con las actividades llevadas a cabo por el Comité de Actividades Antiamericanas, como las delaciones.

Nada más comenzar la película, el prólogo al que nos hemos referido con anterioridad es una declaración de intenciones bastante elocuente. Resulta sorprendente que la censura vetara la famosa escena sexual de las ostras y los caracoles entre Craso y Antonino (Tony Curtis) y no se fijara en frases tan significativas como "su recuerdo se mantiene vivo mientras los últimos vestigios de la esclavitud del hombre agonizan ante nuestros ojos. El sacrificio de Espartaco se convirtió en el triunfo de la humanidad". Esta esperanza en el triunfo de la libertad y el fin de la opresión se vuelve a poner de manifiesto en el final de la película, cuando Antonino, antes de morir, afirma que el espíritu de la revolución no ha muerto y que "él volverá, y con él millones".

Las escenas en que Craso acude a la escuela de Batiato a presenciar una lucha de gladiadores sirven como argumento para hacer un retrato maniqueo de la aristocracia romana, identificable con la clase política estadounidense. Las mujeres aparecen como seres inmorales y caprichosos en su trato hacia los gladiadores. Craso también muestra su crueldad en el asesinato a sangre fría de Graba, quien prefiere morir antes que matar a Espartaco en un combate, es decir, antes que asesinar a un miembro de su misma "clase". En una conversación entre Graco (Charles Laughton) -representante del político inteligente y cínico- y Batiato, el primero expresa una crítica feroz al capitalismo, al expolio de los recursos de otros países, argumento recurrente en la propaganda anticapitalista. En contraposición a este mundo cruel y depravado, la vida en libertad de los esclavos se presenta como una sociedad idílica y feliz, donde todos los hombres y mujeres son iguales, un hecho especialmente conseguido en la representación del campamento del Vesubio. Asimismo, la necesidad de mantener una organización, precisamente lo que había prohibido el gobierno estadounidense con la ilegalización del 
Partido Comunista, se manifiesta en repetidas ocasiones en boca de Espartaco, aludiendo a la necesidad de expandir la revolución y liberar a cuantos esclavos fuera posible.

Dos de los momentos más significativos podemos encontrarlos al final de la película. Mediante la contraposición de las arengas en la batalla final de Espartaco y Craso se comparan las dos formas de pensamiento expresadas en la película. Mientras Craso habla de orden, imperio y castigo, Espartaco alude a la libertad, la lealtad y fraternidad. Esta confrontación se muestra, además de con los diálogos, con otros recursos cinematográficos como la música y las imágenes de niños y ancianos que componen el ejército de esclavos. Pero es sin duda la escena final de la batalla la que más carga simbólica tiene de toda la película. Nos referimos al momento en que Craso ordena a Espartaco a identificarse entre todos los esclavos derrotados. Al incorporarse Espartaco, inmediatamente se va levantando el resto de esclavos y, uno a uno, pronuncian la conocida frase "Yo soy Espartaco", negándose a traicionar a su compañero, motivo por el que encarcelaron a Dalton Trumbo y al contrario que le ocurrió a Howard Fast, delatado por otro comunista. Este momento se ha convertido en una escena clásica de la historia del cine y representa la esencia del comunismo, la importancia del grupo frente al individuo.

Por tanto, volviendo a los objetivos planteados inicialmente, en nuestra opinión esta película es una útil herramienta de trabajo para explicar, de una forma visual y directa, la necesidad de contextualizar históricamente las producciones artísticas con el fin de comprenderlas de forma completa, de acercarnos a ellas desde la perspectiva de su autor. Asimismo, creemos dejar evidente que no todas las películas de temática antigua son válidas para explicar un período histórico concreto, tanto en las enseñanzas medias como superiores. Es necesario valorar la forma de emplear el cine como documento histórico en las aulas, ya que sin una adecuada contextualización podemos caer en el error de transmitir unas ideas preconcebidas, de reproducir unos tópicos gestados en épocas anteriores que no corresponden con la realidad histórica o con las interpretaciones científicas de los hechos narrados en las películas. El caso de Espartaco resulta paradigmático, ya que, como hemos visto, no es correcto identificar a este personaje con el héroe de una revolución contra el sistema esclavista romano. La película es muy útil, en cambio, para mostrar la situación de censura y persecución de una serie de artistas e intelectuales en Estados Unidos a mediados del siglo XX y la 
manera en que se burló la censura empleando un personaje histórico tan carismático como Espartaco.

Para finalizar invitamos al lector a que, cuando en la próxima Semana Santa proyecten la película en televisión -algo que no dejará de sorprendernos ya que la película transcurre entre los años 73 y 71 a.C.-, se acerquen a ella contando con las claves que hemos comentado en este artículo o, si lo prefieren, simplemente disfruten de esta excelente película de romanos. 